\title{
Sleep behavior of infants with infantile hemangioma treated with propranolol-a cohort study
}

\author{
Martin Theiler ${ }^{1,2,3}$ (D) Nicole Knöpfel ${ }^{1,2,3}$ (D) - Susanne von der Heydt ${ }^{4} \cdot$ Agnes Schwieger-Briel $^{1,2,3}$ (D) \\ Isabelle Luchsinger ${ }^{1,2,3}$ (D) - Alexandra Smith ${ }^{5} \cdot$ Kristin Kernland-Lang $^{6} \cdot$ Regula Waelchli $^{1,2,3}$ (D) \\ Kathrin Neuhaus ${ }^{2,3,7}$ (D) Malcolm Kohler ${ }^{8}$ (D) Ralph Gnannt $^{2,3,9}$ (D) Sarah F. Schoch $^{8,10}$ (D) Lisa Weibel $^{1,2,3}$ (D) \\ Salome Kurth ${ }^{8,10,11}$
}

Received: 30 March 2021 /Revised: 1 June 2021 / Accepted: 3 June 2021 / Published online: 18 June 2021

(C) The Author(s) 2021

\begin{abstract}
Sleep problems are frequently reported in infants treated with propranolol for infantile hemangiomas, possibly serving as a marker for a negative impact on central nervous system function. In this cohort study, we objectively investigate the sleep behavior of infants with infantile hemangiomas on propranolol compared to a healthy, untreated control group. Sleep of propranolol-treated infants and controls was investigated using ankle actigraphy and a 24-h diary for 7-10 days at ages 3 and 6 months. The main outcome measures were the Number of Nighttime Awakenings and Sleep Efficiency. The main secondary outcome measures included 24-hour Total Sleep, daytime sleep behavior, and parent-rated infant sleep quality and behavioral development based on the Brief Infant Sleep Questionnaire (BISQ) and the age-appropriate Ages-and-Stages Questionnaire (ASQ), respectively. Fifty-four term-born infants were included in each cohort. No group difference in any investigated parameter was seen at age 3 months. At age 6 months, the propranolol group exhibited a decrease in Sleep Efficiency and a trend towards an increased Number of Nighttime Awakenings compared to the control group. Treated infants at 6 months also had shorter daytime waking periods. 24-hour Total Sleep was unaffected by propranolol. No negative impact of propranolol on subjective sleep quality and behavioral development was noted.
\end{abstract}

Martin Theiler and Nicole Knöpfel contributed equally as co-first authors. Sarah F. Schoch, Lisa Weibel, and Salome Kurth contributed equally as co-senior authors.

\begin{tabular}{ll}
\hline Communicated by Daniele De Luca \\
\hline Martin Theiler \\
martin.theiler@kispi.uzh.ch \\
$\square$ Nicole Knöpfel \\
nicole.knoepfel@outlook.com \\
$\square \quad$ Sarah F. Schoch \\
sarah.schoch@usz.ch \\
$\square$ Lisa Weibel \\
lisa.weibel@kispi.uzh.ch \\
$\square$ Salome Kurth \\
salome.kurth@unifr.ch \\
Susanne von der Heydt \\
info@praxis-vonderheydt.de \\
Agnes Schwieger-Briel \\
agnes.schwieger@kispi.uzh.ch \\
Isabelle Luchsinger \\
isabelle.luchsinger@kispi.uzh.ch
\end{tabular}

\author{
Alexandra Smith \\ alexandra.smith@ksw.ch \\ Kristin Kernland-Lang \\ kristin.kernland@ksb.ch \\ Regula Waelchli \\ regula.braendli@kispi.uzh.ch \\ Kathrin Neuhaus \\ kathrin.neuhaus@kispi.uzh.ch \\ Malcolm Kohler \\ malcolm.kohler@usz.ch \\ Ralph Gnannt \\ ralph.gnannt@kispi.uzh.ch
}

Extended author information available on the last page of the article 
Conclusion: Propranolol exerts a measurable yet mild impact on objectively assessed infants' sleep measures. Behavioral developmental scores were unaffected. Our results support propranolol as first-line therapy for complicated infantile hemangiomas.

What is Known:

- Sleep disorders are frequently reported in infants with infantile hemangiomas treated with propranolol and often lead to treatment discontinuation.

- Investigations of the sleep pattern in this patient group using objective measures are lacking.

What is New:

- The sleep pattern of propranolol-treated infants is assessed using actigraphy and a 24-h sleep diary and compared to healthy, untreated controls.

- Propranolol leads to a decreased sleep efficiency at night and an increased demand of daytime sleep, yet effects are mild overall.

Keywords Sleep $\cdot$ Propranolol $\cdot$ Infantile hemangioma $\cdot$ Actigraphy

\author{
Abbreviations \\ IH Infantile hemangioma \\ BISQ Brief Infant Sleep Questionnaire \\ ASQ Ages-and-Stages Questionnaire \\ PSQI Pittsburgh Sleep Quality Index
}

\section{Introduction}

Systemic propranolol is considered first-line treatment for complicated infantile hemangiomas (IH), given its excellent efficacy and safety $[1,2]$. As a lipophilic molecule, propranolol can cross the blood-brain barrier, leading to concerns for a potentially negative impact on central nervous system (CNS) function [3, 4]. Indeed, parents have reported sleep disturbances such as insomnia, night restlessness, hypersomnia, and nightmares/night terrors in up to $30 \%$ of treated infants $[2,5-8]$. Intolerable sleep problems are the most frequent reason for early propranolol discontinuation, which may result in a poorer overall outcome of treated $\mathrm{IH}[9]$.

Sleep fulfills an essential function in development and is linked to brain maturation, neural reorganization, and processes of learning and memory $[10,11]$. While available data on neurocognitive development of propranolol-treated infants with $\mathrm{IH}$ is reassuring [12-15], further investigation of sleep problems and other CNS effects was recommended in a recent review article [6].

Current knowledge on sleep in propranolol-treated infants is mainly based on studies that rely on parental perception of infant's sleep. Parent reports are a subjective quantification of infant sleep quality, and agreement with objective sleep assessment is poor $[16,17]$. Furthermore, parents might be biased by their doctors and information leaflets mentioning sleep problems as a side effect of propranolol therapy. As infant sleep is highly variable and evolving over time, this information might lead parents to interpret normal variability of infant sleep as problematic [18].
Actigraphy is a convenient and cost-efficient method allowing for the recording of sleep data over extended periods in a natural environment, which may be particularly important in infants [19]. Actigraphy has been shown to correlate well with sleep data obtained from polysomnography [20,21], and its use has significantly increased in pediatric sleep research over the last decades $[22,23]$. Combination with a 24-h diary markedly improves the capture of daytime sleep, which is an integral part of total sleep duration in infancy[24].

In this cohort study, the sleep behavior of propranololtreated infants with $\mathrm{IH}$ was objectively investigated through actigraphy and a 24-h diary at ages 3 and 6 months. In addition, subjective sleep parameters and behavioral development were assessed.

\section{Patients and methods}

\section{Participants}

This cohort study consisted of a prospective cohort of infants with propranolol treatment for $\mathrm{IH}$, whose sleep behavior was assessed over time, and a comparison with an identically designed, historical cohort of untreated infants, whose sleep behavior was assessed in the same manner without any temporal matching. The propranolol cohort consisted of otherwise healthy infants treated with propranolol for a complicated $\mathrm{IH}$. The indication for treatment was made independently from and prior to possible inclusion in this project. Infants were recruited prospectively from the vascular anomalies clinics of the University Children's Hospital Zurich and the Department of Pediatric Surgery, Charite University Medicine, Berlin, from September 2018 through August 2020. The control group was composed of an equal number of untreated matched healthy infants, investigated in an earlier project on infant sleep using the same assessments and study design [10, 24]. Matching criteria included subjects' sex and chronological age at both assessment timepoints at ages 3 and 6 months (maximum difference of equal or less than \pm 10 days at each timepoint). Inclusion criteria were healthy infants aged 
$0-5.5$ months at baseline, born at term (37-42 weeks of gestation), and being mainly breastfed at time of inclusion (at least $50 \%$ of daily nutrition intake) to match with the control group [25]. Only vaginal birth was allowed in the control cohort, whereas no restrictions regarding birth mode were applied in the propranolol group. Exclusion criteria included CNS disorders, acute illness, evidence of brain damage, chronic pediatric disease, and a family background of narcolepsy or significant psychiatric disease. Low birth weight $(<$ $2500 \mathrm{~g}$ ), treatment with medications affecting the sleep-wake cycle (apart from propranolol), and travelling across more than one time zone less than 1 week prior to the measurements also led to exclusion.

Propranolol treatment was performed according to current guidelines $[1,26]$. In case of intolerable side effects, patients were offered off-label treatment with atenolol, a hydrophilic cardio-selective beta-blocker ( $1 \mathrm{mg} / \mathrm{kg} /$ day, single daily dose) [27].

Ethical approval was obtained according to local standards (Cantonal ethics committee, BASEC 2018-01366, and 201600730), and study procedures were consistent with the declaration of Helsinki. Written parental consent was obtained in all subjects before data collection.

\section{Study procedures}

Assessments were scheduled at ages 3 and 6 months, within a 1-month window centered around the target age. For subjects initiating propranolol treatment after age 3 months, only one assessment at 6 months was performed. In those infants who stopped propranolol and were switched to atenolol, additional measurements on atenolol were performed within the first 2 weeks after atenolol initiation.

Demographic data and patient characteristics were assessed using patient charts and questionnaire data.

Sleep-wake behavior was quantified for 7-10 days at each timepoint, simultaneously acquiring actigraphy and a 24-h diary in the infant's natural environment (usually at home). GENEActiv movement sensors (Activinsights Ltd, Kimbolton, UK, 43x40x13mm, MEMS sensor, 16 g, $30 \mathrm{~Hz}$ Frequency recording resolution) were attached to the infant's left ankle in a modified sock (Fig. 1).

The 24-h diary was completed in 15-min resolution by caregivers in parallel to the actigraphy recording. Diary data included reporting on infant sleep, external movements occurring during sleep (e.g., sleeping in a stroller/car), feeding episodes, propranolol administration, and bedtimes (clock time) (Fig. 1).

Caregivers in both cohorts completed the Brief Infant Sleep Questionnaire (BISQ) during the measurements, which is a validated survey to assess infant sleep [28]. To investigate the impact of the infants' sleep behavior on the whole family, both parents' sleep quality was assessed using the Pittsburgh Sleep Quality Index (PSQI) [29].

The behavioral development of infants in both cohorts was investigated with the parent-completed age-appropriate Agesand-Stages questionnaire [30].

The Hemangioma Activity Score (HAS) was used to document $\mathrm{IH}$ treatment response in the propranolol cohort [31].

\section{Sleep analysis}

Actigraphy data was processed according to in-laboratory standards [10,24]. A published algorithm was applied to identify infant sleep and wake periods [19]. By applying a previously validated 6-step modification, a better fit with the 24-h diary was achieved [24].

\section{Primary outcomes}

The primary outcomes were the objectively assessed Number of Awakenings per hour of Night Sleep and Sleep Efficiency (\%), which is defined as the ratio of Total Sleep Time (at night) and Sleep Opportunity (time spent in bed), at 3 and 6 months [10]. Sleep Efficiency may be viewed as a marker for overall nighttime sleep quality, as decreased values can correspond to problems falling asleep, increased sleep fragmentation, early waking up, or a combination thereof. These two variables represent a sleep composite that we have previously reported as Sleep Activity [10].

\section{Secondary outcomes}

Secondary objective sleep measures included 24-hour Total Sleep and addressed the four remaining infant sleep composites, which we have previously identified as Sleep Night, Sleep Day, Sleep Timing, and Sleep Variability [10]. Accordingly, we selected the variables Sleep Period (time between Sleep Onset and Sleep Offset at night in minutes, which represents Sleep Night), Longest Wake (longest continuous wake period during the day in minutes, which indirectly correlates with the accumulation of daytime sleep need and thus Sleep Day), Sleep Offset (morning wake time in hours, which represents Sleep Timing), and Variability of Sleep Period (standard deviation of Sleep Period across measurement days (in minutes), which represents Sleep Variability).

Secondary outcomes also encompassed subjective data according to the parent-completed questionnaires, including data on infant sleep (24-hour Total Sleep, Number of Nighttime Awakenings, Duration of Daytime Sleep, and Sleep Problems), the parents' sleep quality, and the behavioral development at ages 3 and 6 months. 
Fig. 1 Methods used for assessing objective sleep measures. Attachment (a) of the Actigraph (b) in a special sock on the left ankle. Representative example of a 24-hour diary (c)

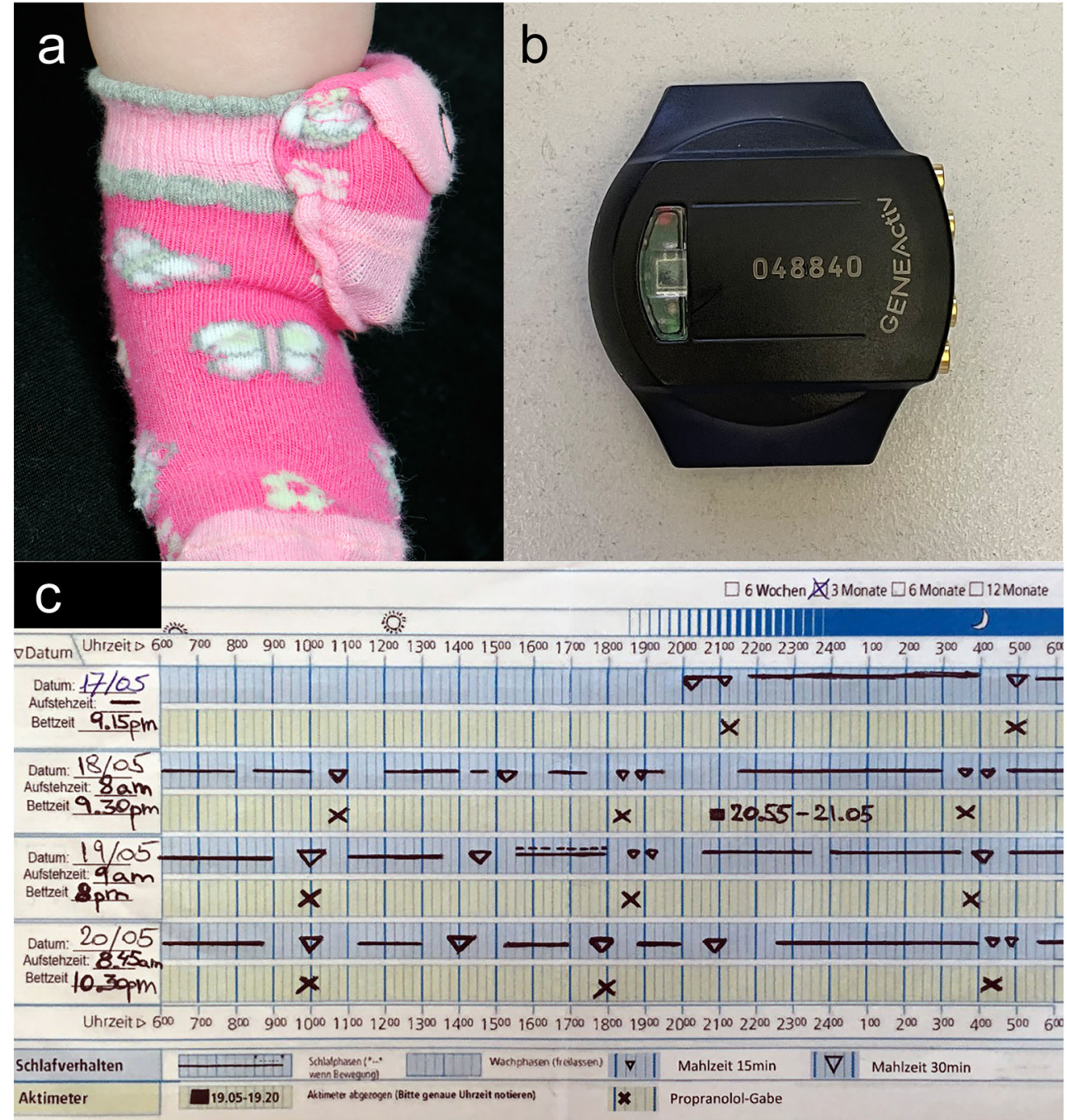

\section{Sample size calculation}

Determination of the sample size was based on a two-sample t-test power calculation with a two-sided significance level of 0.05 to give greater than or equal to $80 \%$ power to detect differences of $\geq 25 \%$ in the Number of Nighttime Awakenings in propranolol-treated infants versus controls at 6 months. This resulted in 44 required datasets per group.

\section{Statistical analysis}

Statistical analysis was done using R [32] and RStudio [33] and the packages ggplot2, MASS, mosaic, kableExtra, pander, lme4, lmerTest, cowplot, purr, qwraps2, psych, and dpylr [34-39]. We compared the demographics of the control and propranolol cohort by applying chi-square and t-tests. The efficacy of treatment (baseline, T1, and T2) was assessed using a multilevel model (lmer), with varying intercepts for each patient. Differences in objective and subjective sleep variables, as well as parental sleep quality and behavioral development, were assessed using linear models with group (propranolol/ control) as predictors and exact age at measurement start, sex, and gestational age at birth as control variables. Each timepoint was analyzed separately, as we did not have complete datasets for either timepoint, and not enough timepoints to utilize a multilevel model. Alpha level was set to $\mathrm{p}<0.05$. Because we included many objective and subjective sleep variables, we controlled for multiple comparisons by applying a False Discovery Rate (FDR) correction (Benjamini-Hochberg).

\section{Results}

\section{Participants}

Fifty-four subjects were included in each cohort (detailed patient characteristics are shown in Table 1). There were no significant differences between cohorts except for a lower gestational age in the propranolol group (mean, 39.3 vs. 40.0 weeks, $p=0.001$ ). Thirty-four and 47 datasets were 
available to calculate objective sleep parameters at 3 and 6 months, respectively. For 7 participants, only 3 -month assessments were available due to treatment switch to atenolol before age 6 months $(n=2)$, vacation in the 6-month measurement window $(n=1)$, loss to follow-up $(n=2)$, and withdrawal from the study $(n=2)$.

\section{Treatment characteristics}

A total of $70 \mathrm{IH}$ were treated in 54 participants. The mean propranolol dose was $1.9 \mathrm{mg} / \mathrm{kg} /$ day at both measurements, and the mean duration of propranolol exposure at the beginning of the measurements was 2.9 and 10.8 weeks at 3 and 6 months, respectively. For details on treatment, please refer to Table 2. Therapy was highly effective, as evidenced by a statistically significant decrease in the HAS across the study period ( $\mathrm{p}<0.001$, Fig. 2). No serious adverse events occurred. Three patients (5.6\%) were switched to atenolol at the age of 3 months $(\mathrm{n}=2)$ and 6 months $(\mathrm{n}=1)$, respectively, due to intolerable sleep problems. 3-month objective sleep measures (actigraphy, 24-h diary)

No differences in the objective sleep behavior were detected between the two infant groups (all FDR corrected p-values > 0.05 , Table 3). Boxplots displaying objective sleep measures are shown in Fig. 3.

\section{6-month objective sleep measures (actigraphy, 24-h diary)}

A significant reduction in infant Sleep Efficiency was detected in the propranolol group (mean \pm SD: $90.2 \pm 5.0 \%$ ) vs. the control group at age 6 months $(92.1 \pm 3.6 \%$; FDR corrected $\mathrm{p}=0.032$ ). In concordance, the Number of Awakenings per hour of Night Sleep was increased; this was, however, not significant, when correcting for multiple comparisons (FDR corrected $\mathrm{p}=0.08$ ). The Longest Wake during the day was significantly shorter, by about $25 \mathrm{~min}$, in treated infants (mean $\pm \mathrm{SD}, 193.0 \pm 28.3 \mathrm{~min}$ )

Table 1 Patient characteristics

Propranolol cohort $(n=54)$

$11(20.4)$
$43(79.6)$
$39.3 \pm 1.2(37.0-42.0)$
$3371 \pm 448(2535-4150)$
$35(64.8)$
$14(25.9)$
$5(9.3)$
39
1
7
7
$34.0 \pm 4.1(26.0-41.0)$
$35.7 \pm 5.2(27.0-46.0)$

$19.2 \pm 28.1$

$24.5 \pm 32.7$

$34(8 / 26)$

$2.9 \pm 0.2(2.4-3.2)$

Mean age at initiation (months), mean \pm SD (range)

6-month assessments

Number of available recordings (male/female)

Mean age at initiation (months), mean \pm SD (range)
$47(10 / 37)$

$5.8 \pm 0.3(5.5-6.4)$
Controls $(n=54)$

$\mathrm{p}=*$

Gender

Female, n $(\%)$

Gestational age at birth (weeks), mean \pm SD (range)

Birth mode

Vaginal delivery, $\mathrm{n}(\%)$

Unknown, n (\%)

Caucasian, $\mathrm{n}$

Hispanic, $\mathrm{n}$

Unknown, $\mathrm{n}$

At age 3 months, mean \pm SD

At age 6 months, mean \pm SD

$28.9 \pm 40.5$

$25.1 \pm 34.6$

0.93

$34(8 / 26)$

$2.9 \pm 0.2(2.4-3.4)$

0.80

$47(10 / 37)$

$5.8 \pm 0.2(5.5-6.2)$

0.48

*Welch two-sample t-test/chi-square test 
Table 2 Propranolol treatment characteristics. $I H$ infantile hemangioma

Total number of treated $\mathrm{IH}$

70

IH location

Head/neck, n (\%)

$47(67.1)$

Trunk, n (\%)

$13(18.6)$

Extremities, $\mathrm{n}(\%)$

$10(14.3)$

Reason for treatment

Life threatening $\mathrm{IH}, \mathrm{n}(\%)$

$0(0)$

Function threatening $\mathrm{IH}(\%)$

$21(38.9)$

(Risk of) Ulceration (\%)

$14(25.9)$

Esthetic (\%)

$34(63.0)$

Age at propranolol initiation (months), mean $\pm \mathrm{SD}$ (range)

$3.2 \pm 1.51(1.1-6.3)$

Propranolol dose $(\mathrm{mg} / \mathrm{kg} /$ day $)$, mean $\pm \mathrm{SD}$ (range)

At initiation

$2.0 \pm 0.3(0.8-3)$

At 3 months

$1.9 \pm 0.4(1-3)$

At 6 months

$1.9 \pm 0.3(1-3)$

Duration of propranolol exposure at beginning of 3-month measurements (weeks), mean \pm SD (range)

$2.9 \pm 1.9(0-5.9)$

Duration of propranolol exposure at beginning of 6-month measurements (weeks), mean $\pm \mathrm{SD}$ (range)

$10.8 \pm 6.8(0-20.1)$

Hemangioma Activity Score (HAS)

At initiation \pm SD (range)

$4.4 \pm 0.9(2-6)$

At 3 months \pm SD (range)

$3.3 \pm 1.0(1.3-5.5)$

At 6 months $\pm \mathrm{SD}$ (range)

$2.2 \pm 1.1(0-5)$

Serious adverse events, $\mathrm{n}(\%)$

$0(0)$

Subjects switched to atenolol due to sleep disturbance, $\mathrm{n}(\%)$

$3(5.6)$

Fig. 2 Treatment response of infantile hemangiomas according to the Hemangioma Activity Score (HAS) showing a statistically significant decrease over the study period $(\mathrm{p}<0.001)$

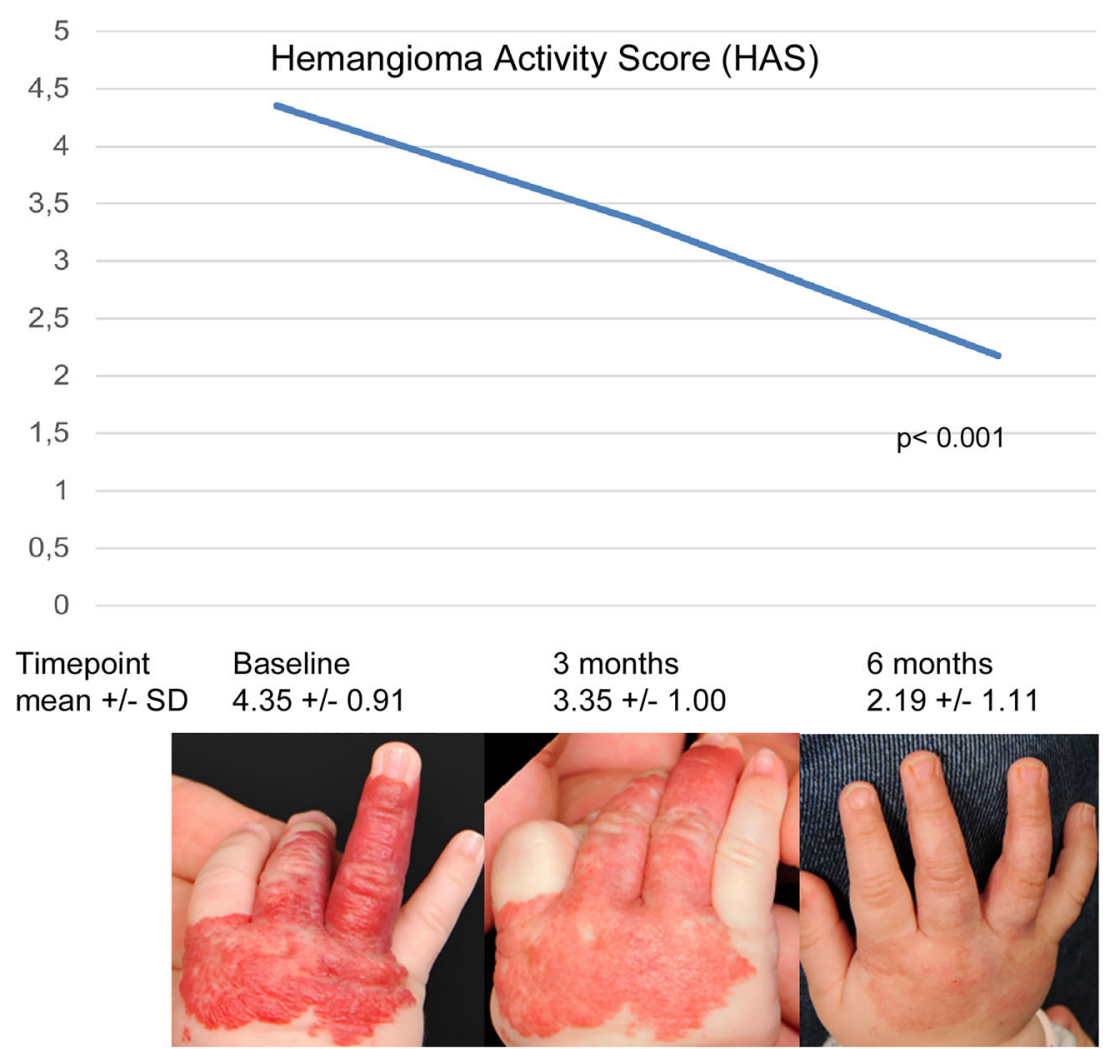




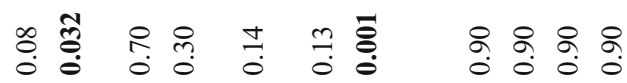

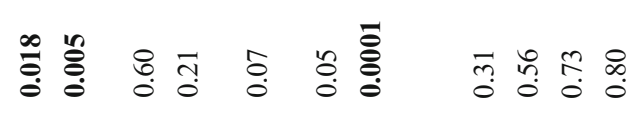

กิ่

융

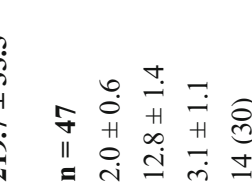

字

ठํํㅇ ते

$\overrightarrow{\mathrm{N}} \frac{\mathrm{H}}{\mathrm{i}}$

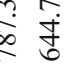

ते

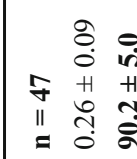

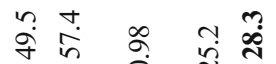

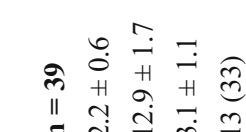

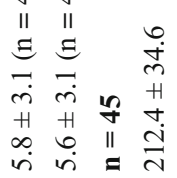

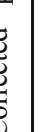

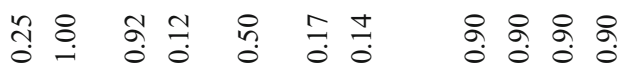

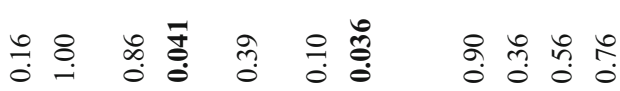

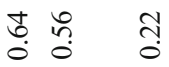

สิส

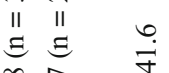

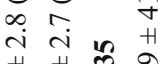

ชู ๆ

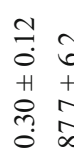

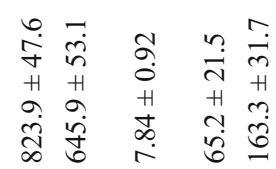

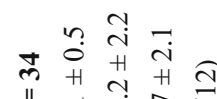

ल

II II

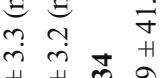

ठั

$=\vec{i} \dot{I}$

సิํำ

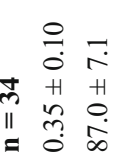

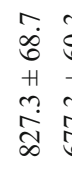

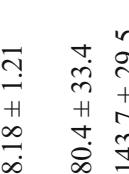

ิㅡ

II

में ते मे

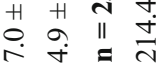

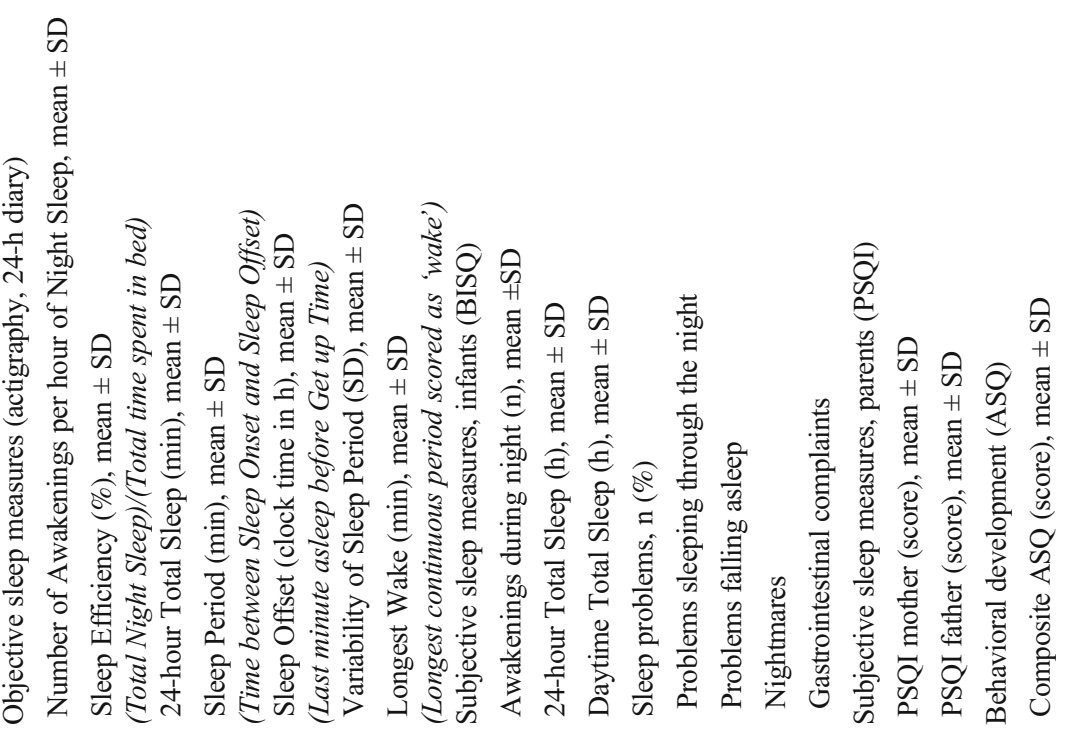



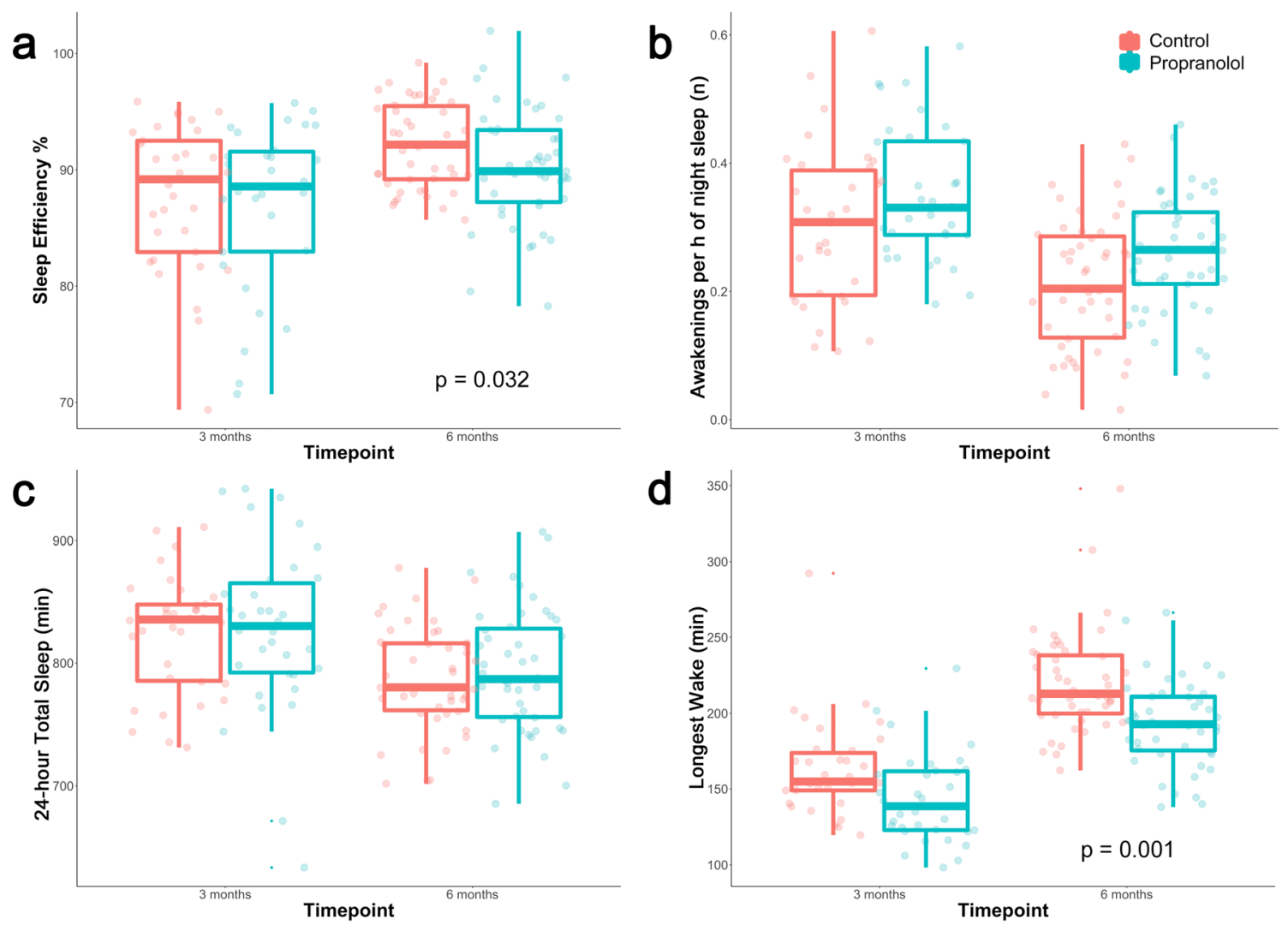

Fig. 3 Boxplots of the main objective sleep measures. a Sleep Efficiency (\%), b Number of Awakenings per hour of Night Sleep, c 24-hour Total Sleep (min), d Longest Wake (min). Sleep Efficiency and Longest Wake showed statistically significant differences between groups at age 6 months

than controls $(219.7 \pm 33.5 \mathrm{~min}$; FDR corrected $\mathrm{p}=$ 0.001 ), reflecting an increased demand for daytime sleep in the propranolol group. No differences were evident in the other objective sleep variables, including 24-h Total Sleep (all FDR corrected p-values $>0.05$ ). All results are shown in Table 3 and Fig. 3.

\section{Subjective sleep measures (BISQ, PSQI)}

No statistically significant differences occurred in the subjective infant sleep parameters at 3 and 6 months, as demonstrated in Table 3 and Fig. 4 (all FDR corrected pvalues $>0.05$ ). About $15 \%$ and $30 \%$ of parents reported sleep problems in both groups at age 3 and 6 months, respectively. Nightmares $(n=2)$ and nighttime gastrointestinal complaints $(n=3)$ were only reported in the propranolol group at 6 months.

Parents' sleep quality as assessed by means of the PSQI did not differ between groups at either timepoint $(\mathrm{p}>0.05)$.

\section{Behavioral development (ASQ)}

Scoring on the global age-appropriate Ages-and-Stages Questionnaire did not differ between groups at both 3 and 6 months $(\mathrm{p}>0.05)$. For details, see Table 3 and Fig. 4.

\section{Atenolol treatment}

Three patients ( 2 female/ 1 male) were switched from propranolol to atenolol therapy due to severe sleep problems. The parents of these 3 infants complained about infants' difficulties falling asleep and nightly agitation, while one infant additionally experienced nightmares/night terrors. In concordance with these symptoms, all three patients had a relatively low Sleep Efficiency with propranolol between 70.7 and $79.5 \%$ (Table 4, Fig. 5). Their families reported moderate to considerable improvement of sleep after switching treatment. The low number of subjects precluded statistical analysis. However, descriptively, the Sleep Efficiency increased in all three infants (increase ranged from +2.6 to $9.0 \%$ ). Additionally, the Longest Wake period during the day increased by 8.7 to $30.3 \mathrm{~min}$. 24-hour Total Sleep decreased by $24.3 \mathrm{~min}$ and increased by 5.6 and $33.2 \mathrm{~min}$ in the three infants, respectively.

\section{Discussion}

This is the largest study objectively assessing sleep in infants treated with propranolol for IH. Our data show that propranolol exposure mainly affects infants' nighttime sleep 

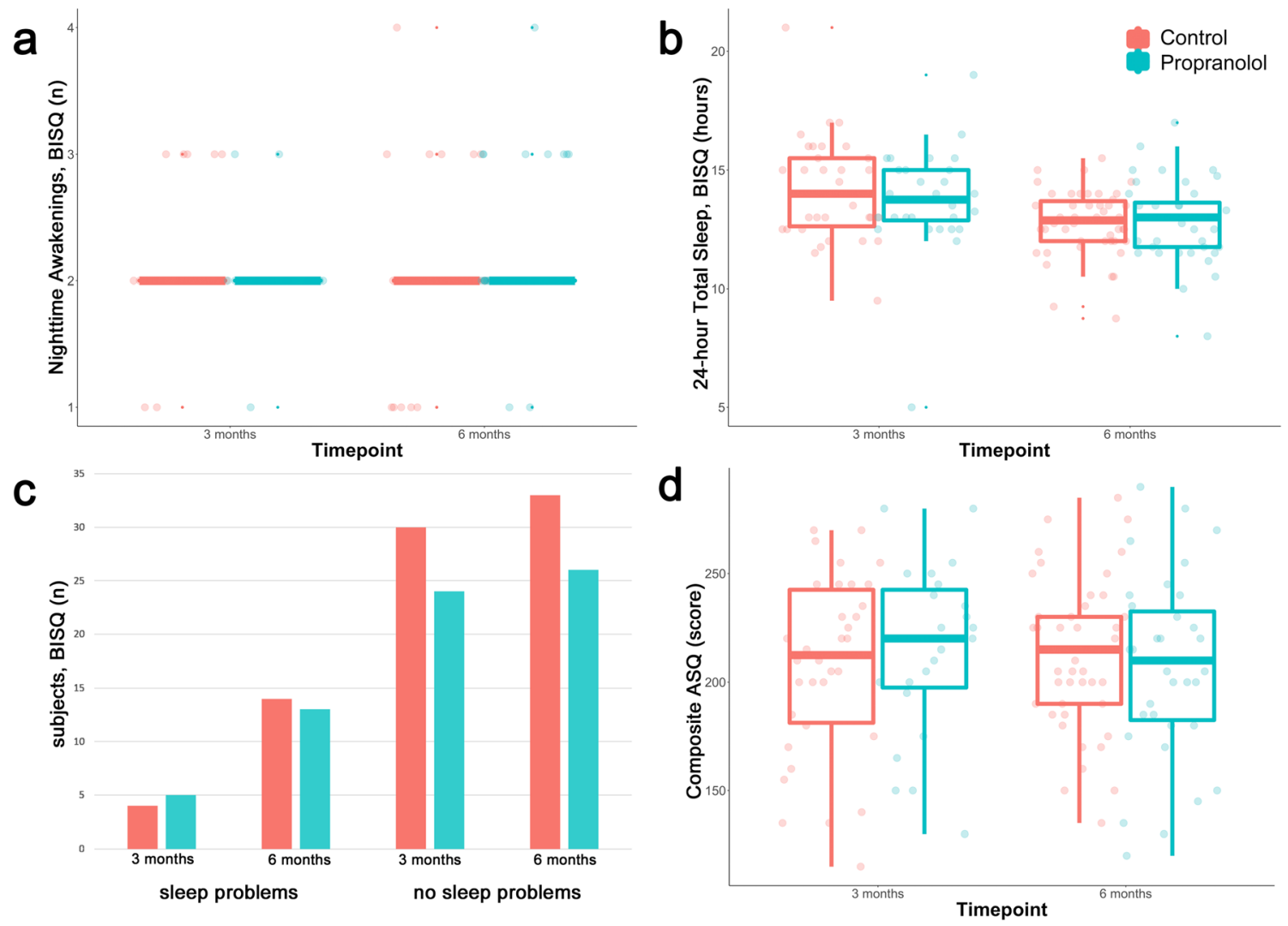

Fig. 4 Main results of subjective sleep measures (BISQ) and assessment of behavioral development (ASQ). a Number of Nighttime Awakenings, b 24-hour Total Sleep (hours), c Frequency of sleep problems reported by parents, d Scoring on the global ASQ assessing overall behavioral

development. No statistically significant differences were found in any of these parameters. BISQ: Brief Infant Sleep Questionnaire. ASQ: Agesand-Stages Questionnaire

consolidation by reducing Sleep Efficiency and, at trend level, increasing the Number of Nighttime Awakenings, compared to untreated infants at age 6 months. This is clearly in line with previous reports on sleep disturbance in propranolol-treated infants $[2,4-7]$ and publications on adult patients reporting increased nighttime awakenings, insomnia, and nightmares while on propranolol and other beta-blockers [40-43]. However, infant 24-hour Total Sleep was not affected by

propranolol. This may suggest a compensatory mechanism, such that decreased Sleep Efficiency at night is compensated by increased napping during the day. This concept was indeed evidenced by significantly reduced Longest Wake periods in infants receiving propranolol.

While the reduction in Longest Wake might be a mere catchup phenomenon, it could also be due to a direct influence of propranolol on the CNS [3]. We have previously proposed that

Table 4 Objective sleep measures in patients switched from propranolol to atenolol $(n=3)$

\begin{tabular}{|c|c|c|c|c|c|c|c|}
\hline Patient code & $\begin{array}{l}\text { Awakenings per hour of } \\
\text { night sleep (n) }\end{array}$ & $\begin{array}{l}\text { Sleep } \\
\text { efficiency } \\
(\%)\end{array}$ & $\begin{array}{l}\text { 24-hour total } \\
\text { sleep (min) }\end{array}$ & $\begin{array}{l}\text { Sleep } \\
\text { Period } \\
(\min )\end{array}$ & $\begin{array}{l}\text { Sleep offset } \\
\text { (clock time in h) }\end{array}$ & $\begin{array}{l}\text { Variability of Sleep } \\
\text { Period (SD) }\end{array}$ & $\begin{array}{l}\text { Longest } \\
\text { Wake (min) }\end{array}$ \\
\hline $\begin{array}{l}\text { IHPS24 on propranolol } \\
\quad \text { (age } 3 \text { months) }\end{array}$ & 0.30 & 70.7 & 764.0 & 788.7 & 11.1 & 146.3 & 166.4 \\
\hline IHPS 24 on atenolol & 0.33 & 76.2 & 739.5 & 733 & 11.2 & 119.3 & 196.8 \\
\hline $\begin{array}{l}\text { IHPS45 on propranolol } \\
\text { (age } 3 \text { months) }\end{array}$ & 0.52 & 74.4 & 790.4 & 687.7 & 6.7 & 83.4 & 126.0 \\
\hline IHPS45 on atenolol & 0.47 & 77.0 & 796.0 & 703 & 6.1 & 108.3 & 141.5 \\
\hline $\begin{array}{l}\text { IHPS49 on propranolol } \\
\text { (age } 6 \text { months) }\end{array}$ & 0.36 & 79.5 & 700.2 & 538.8 & 8.2 & 77.4 & 201.3 \\
\hline IHPS49 on atenolol & 0.35 & 88.6 & 733.4 & 619.2 & 8.8 & 49.9 & 210.0 \\
\hline
\end{tabular}



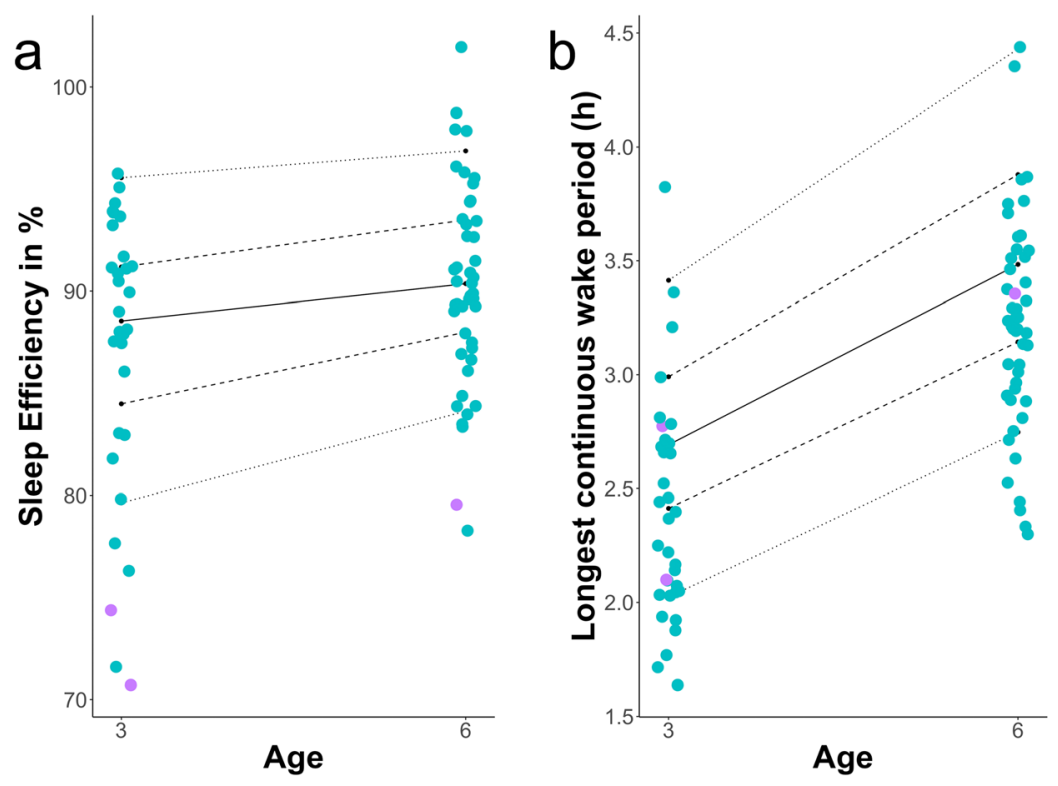

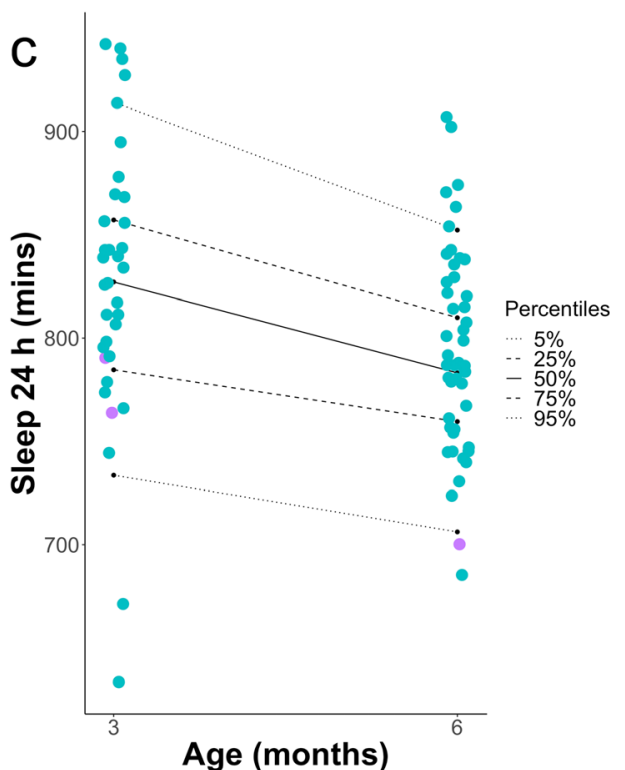

Fig. 5 Plots showing the distribution of the objective sleep measurement results of subjects in the propranolol group in relation to the full control cohort (152 infants, percentiles) at 3 and 6 months [10]. Blue dots indicate subjects on propranolol; purple dots $(n=3)$ indicate subjects on propranolol that had to be switched to atenolol later due to decreased sleep quality. a Sleep Efficiency, b Longest Continuous Waking Episode, c 24-hour Total Sleep daytime sleep and Longest Wake are markers of general maturation in infancy, based on the observation that they are associated with developmental outcomes of behavior [10].

In contrast to the observations at age 6 months, we did not find any effects of propranolol on sleep behavior at age 3 months. Sleep behavior is continually evolving throughout the first year of life and even beyond - a process of increasing consolidation of the sleep-wake rhythm. Accordingly, Sleep Efficiency is expected to be decreased at age 3 compared to age 6 months, as was found in this study. Possible effects of propranolol on Sleep Efficiency might, therefore, be obscured. Additionally, capturing sleep behavior using actigraphy is more difficult in younger children, due to less vigorous movements in waking phases. Finally, it may be possible that the effects of propranolol on sleep might be increasing with longer exposure to the medication.

Interestingly, the subjective sleep measures in this study indicated no differences in the infants' and parents' sleep quality between groups, except for the occurrence of nightmares in 2 patients $(5.1 \%)$ in the propranolol group at age 6 months. These results are surprising as they contradict the objective findings of this study and reports from the literature [2, 5], hence supporting previous studies showing that agreement between parent reports and objective sleep measurements is insufficient[16, 17].

While sleep problems in infants may have immediate negative effects on infant-parent bonding and lead to parental stress and depression [44, 45], possible long-term adverse effects on the infant's behavioral development are of even greater importance $[44,46]$. A recent review article reported no significant association of propranolol with CNS effects. However, there seemed to be a trend for increased CNS effects of propranolol compared to other non-corticosteroid treatments or placebo. Of note, propranolol appeared to have a safer profile of CNS effects than corticosteroids, the former mainstay treatment for $\mathrm{IH}$ [6].

Current data on behavioral development of children with IH treated with propranolol in infancy are available up to age 7 years and very reassuring [12-15]. In line with this, we did not detect any differences in the behavioral developmental scoring on the Ages-and-Stages questionnaire between treated and untreated children at 3 and 6 months.

Whereas the group differences in Sleep Efficiency and Longest Wake were statistically significant at infant age 6 months, it may be debated whether these are clinically relevant. If we assume an infant to spend $12 \mathrm{~h}$ in bed at night, the mean difference of $1.9 \%$ in Sleep Efficiency between groups corresponds to an absolute difference of $\sim 14 \mathrm{~min}$ in total nighttime sleep, which might be negligible. Taken together with our findings of unaffected 24-hour Total Sleep, a comparable subjective sleep quality, and normal behavioral development in both groups, we conclude that the impact of propranolol on the sleep behavior of infants, in general, is small. Along these lines, a recent pilot study assessing sleep quality in infants treated with propranolol based on the BISQ and actigraphy in a small proportion of included children did not find a significant impairment of sleep quality and pattern [47].

Nevertheless, a minority of infants seems particularly susceptible to propranolol in terms of sleep, as evidenced by three infants $(5.6 \%)$ in our study requiring early treatment discontinuation. These infants showed a low Sleep Efficiency on 
propranolol, which improved when they were switched to atenolol. While the number of atenolol-treated infants in this study was low, our findings are in keeping with previous reports suggesting that infants with sleep problems on propranolol might benefit from hydrophilic beta-blockers such as atenolol [27, 48]. Larger-scale studies targeting specifically the small subgroup of infants whose sleep is affected by propranolol are required to understand why high susceptibility towards sleep disturbances under propranolol can in rare cases occur.

How beta-blockers might influence sleep regulation is not yet fully elucidated. Direct action on centrally located beta-adrenergic, noradrenergic, and serotonin receptors, suppression of nighttime melatonin secretion, and even indirect effects via nitric oxide and hydrogen peroxide release have all been postulated [40, $49,50]$. Interestingly, melatonin supplementation was shown to improve sleep in adults treated with beta-blockers [49].

\section{Limitations}

As IH are associated with preterm birth and low birth weight, a significant proportion of propranolol-treated infants had to be excluded [51]. Given the many confounders associated with preterm infants' sleep behavior (e.g., immature brain development, respiratory problems, hospital admission in a neonatal care unit), only term-born subjects were included in this study. Therefore, we cannot exclude that effects of propranolol on sleep behavior of (previously) preterm infants might be different. In addition, we acknowledge that the used methodological approach, notably the use of historical controls, may cause secular biases and other potential distortion.

\section{Conclusions}

This is the largest study to examine with objective measures whether propranolol treatment of infants with IH is linked to altered sleep behavior. While propranolol therapy was associated with a reduction in Sleep Efficiency and an increase in nighttime awakenings at age 6 months, 24-hour Total Sleep did not differ between treatment and control groups. This observation suggests that infants compensate the effect of propranolol on nighttime sleep throughout the day. Future research should address whether increased napping indeed merely compensates for missed nighttime sleep - or whether the altered daytime sleep in the propranolol group is indicative of potential effects on the CNS and its maturation. No differences in parent-rated infants' and parents' subjective sleep quality were detected, and infants on propranolol had normal behavioral development at ages 3 and 6 months. The overall impact of propranolol on infants' sleep seemed mild.

Acknowledgements We thank all the families for participating in this project. A further thank goes to Margareta Theiler - Imesch for her support with the study material. We would also like to thank the reviewers for their sophisticated comments and input on this manuscript.

Role of funder None of the funders mentioned had a role in the design and conduct of the study.

Availability of data and material The authors confirm that the data supporting the findings of this study are available within the article.

Code availability N/A.

Authors' Contributions All authors had full access to all the data in the study and take responsibility for integrity of the data and accuracy of data analysis.

Dr. Theiler conceptualized and designed the study, coordinated and supervised data collection, drafted the initial manuscript, and reviewed and revised the manuscript.

Dr. Schoch conceptualized and designed the study, designed the data collection instruments, carried out the data analysis, drafted the initial manuscript, and reviewed and revised the manuscript.

Prof Kurth conceptualized and designed the study, designed the data collection instruments, supervised the project, and reviewed and revised the manuscript.

Dr. Knöpfel coordinated data collection, drafted the initial manuscript, and reviewed and revised the manuscript.

Dr. Weibel conceptualized and designed the study and reviewed and revised the manuscript.

Dr von der Heydt coordinated and performed data collection and reviewed and revised the manuscript.

Drs. Schwieger-Briel, Luchsinger, Wälchli, Kernland-Lang, Smith, Kohler, Neuhaus, and Gnannt were involved in data collection and reviewed and revised the manuscript for important intellectual content.

Funding Open Access funding provided by Universität Zürich. Sarah F. Schoch and Salome Kurth received funding by the University of Zurich (Clinical Research Priority Program "Sleep and Health," Forschungskredit FK-18-047, Faculty of Medicine), the Swiss National Science Foundation (PCEFP1-181279, P0ZHP1-178697), Foundation for Research in Science and the Humanities (STWF-17-008), and the Olga Mayenfisch Stiftung.

Martin Theiler received a research prize of the German foundation for pediatric dermatology (Deutsche Stiftung Kinderdermatologie, DSK) supporting this work.

\section{Declarations}

Ethics approval Ethical approval was obtained according to local standards (Cantonal ethics committee, BASEC 2018-01366, and 201600730)

Consent to participate Written parental consent was obtained in all subjects before data collection.

Consent for publication Written parental consent for publication was obtained in all subjects.

Conflict of interest Martin Theiler received honoraria from Pfizer, Janssen, Novartis, and Eli Lilly for investigator services, and from Sanofi-Aventis, Pfizer, and Novartis for participation on advisory boards and for consultancy. Lisa Weibel received honoraria from AbbVie, Pfizer, Eli Lilly, and Novartis for investigator services, and from Pierre Fabre, Sanofi-Aventis, Pfizer, Permamed, and Novartis for participation on advisory boards, as a speaker, and for consultancy. The other authors declared no conflicts of interest related to the content of this manuscript. 
Open Access This article is licensed under a Creative Commons Attribution 4.0 International License, which permits use, sharing, adaptation, distribution and reproduction in any medium or format, as long as you give appropriate credit to the original author(s) and the source, provide a link to the Creative Commons licence, and indicate if changes were made. The images or other third party material in this article are included in the article's Creative Commons licence, unless indicated otherwise in a credit line to the material. If material is not included in the article's Creative Commons licence and your intended use is not permitted by statutory regulation or exceeds the permitted use, you will need to obtain permission directly from the copyright holder. To view a copy of this licence, visit http://creativecommons.org/licenses/by/4.0/.

\section{References}

1. Krowchuk DP, Frieden IJ, Mancini AJ, Darrow DH, Blei F, Greene AK, Annam A, Baker CN, Frommelt PC, Hodak A, Pate BM, Pelletier JL, Sandrock D, Weinberg ST, Whelan MA, SUBCOMMITTEE ON THE MANAGEMENT OF INFANTILE HEMANGIOMAS (2019) Clinical practice guideline for the management of infantile hemangiomas. Pediatrics 143:e20183475. https://doi.org/10.1542/peds.2018-3475

2. Léauté-Labrèze $\mathrm{C}$, Hoeger $\mathrm{P}$, Mazereeuw-Hautier $\mathrm{J}$, Guibaud L, Baselga E, Posiunas G, Phillips RJ, Caceres H, Lopez Gutierrez JC, Ballona R, Friedlander SF, Powell J, Perek D, Metz B, Barbarot S, Maruani A, Szalai ZZ, Krol A, Boccara O, FoelsterHolst R, Bosch MI, Su J, Buckova H, Torrelo A, Cambazard F, Grantzow R, Wargon O, Wyrzykowski D, Roessler J, BernabeuWittel J, Valencia AM, Przewratil P, Glick S, Pope E, Birchall N, Benjamin L, Mancini AJ, Vabres P, Souteyrand P, Frieden IJ, Berul CI, Mehta CR, Prey S, Boralevi F, Morgan CC, Heritier S, Delarue A, Voisard JJ (2014) A randomized, controlled trial of oral propranolol in infantile hemangioma. N Engl J Med 372:735-746. https:// doi.org/10.1056/NEJMoa1404710

3. Langley A, Pope E (2015) Propranolol and central nervous system function: potential implications for paediatric patients with infantile haemangiomas. Br J Dermatol 172:13-23. https://doi.org/10.1111/ bjd.13379

4. Xerfan EMS, Andersen ML, Facina AS, Tufik S, Tomimori J (2020) Sleep disturbances as an adverse effect of propranolol use in children with infantile hemangioma. World J Pediatr 16:537538. https://doi.org/10.1007/s12519-019-00335-2

5. Léaute-Labrèze $\mathrm{C}$, Boccara $\mathrm{O}$, Degrugillier-Chopinet $\mathrm{C}$ et al (2016) Safety of oral propranolol for the treatment of infantile hemangioma: a systematic review. Pediatrics 138:e20160353. https://doi.org/ 10.1542/peds.2016-0353

6. Thai T, Wang C-Y, Chang C-Y, Brown J (2019) Central nervous system effects of oral propranolol for infantile hemangioma: a systematic review and meta-analysis. J Clin Med 8:268. https://doi.org/ $10.3390 / \mathrm{jcm} 8020268$

7. Socchi F, Bigorre M, Normandin M, Captier G, Bessis D, Mondain M, Blanchet C, Akkari M, Amedro P, Gavotto A (2020) Hemangiol ${ }^{\circledR}$ in infantile haemangioma: a paediatric postmarketing surveillance drug study. Br J Clin Pharmacol 87:1-11. https://doi.org/10.1111/bcp.14593

8. Yang H, Hu DL, Shu Q, Guo XD (2019) Efficacy and adverse effects of oral propranolol in infantile hemangioma: a metaanalysis of comparative studies. World J Pediatr 15:546-558. https://doi.org/10.1007/s12519-019-00285-9

9. Ji Y, Chen S, Wang Q, Xiang B, Xu Z, Zhong L, Yang K, Lu G, Qiu L (2018) Intolerable side effects during propranolol therapy for infantile hemangioma: frequency, risk factors and management. Sci Rep 8:1-7. https://doi.org/10.1038/s41598-018-22787-8
10. Schoch SF, Huber R, Kohler M, Kurth S (2020) Which are the central aspects of infant sleep? The dynamics of sleep composites across infancy. Sensors 20:7188

11. El-Sheikh M, Sadeh A (2015) I. sleep and development: introduction to the monograph. Monogr Soc Res Child Dev 80:1-14. https://doi.org/10.1111/mono.12141

12. Moyakine AV, Kerstjens JM, Spillekom-Van Koulil S, Van Der Vleuten CJM (2016) Propranolol treatment of infantile hemangio$\mathrm{ma}(\mathrm{IH})$ is not associated with developmental risk or growth impairment at age 4 years. J Am Acad Dermatol 75:59-63.e1. 75:5963.e1. https://doi.org/10.1016/j.jaad.2016.02.1218

13. Moyakine AV, Spillekom-van Koulil S, van der Vleuten CJM (2017) Propranolol treatment of infantile hemangioma is not associated with psychological problems at 7 years of age. J Am Acad Dermatol 77:105-108. https://doi.org/10.1016/j.jaad.2017.01.025

14. González-Llorente N, del Olmo-Benito I, Muñoz-Ollero N, Descalzo MA, García-Doval I, Torrelo A (2017) Study of cognitive function in children treated with propranolol for infantile hemangioma. Pediatr Dermatol 34:554-558. https://doi.org/10.1111/pde. 13229

15. Li L, Wei L, Xu ZG, Ma L (2019) No increased risks associated with propranolol treatment for infantile hemangioma in preterm infants were identified at 3 years of age. Am J Clin Dermatol 20: 289-293. https://doi.org/10.1007/s40257-018-00419-1

16. Werner H, Molinari L, Guyer C, Jenni OG (2008) Agreement rates between actigraphy, diary, and questionnaire for children's sleep patterns. Arch Pediatr Adolesc Med 162:350-358. https://doi.org/ 10.1001/archpedi.162.4.350

17. Quante M, Hong B, Ash T et al (2020) Associations between subjectively and objectively measured sleep duration and timing in infants at age 6 months. Sleep 2020 Oct 24:zsaa217. 44. https:// doi.org/10.1093/sleep/zsaa217

18. Iglowstein I, Jenni OG, Molinari L, Largo RH (2003) Sleep duration from infancy to adolescence: reference values and generational trends. Pediatrics 111:302-307. https://doi.org/10.1542/peds.111.2. 302

19. Sadeh A, Acebo C, Seifer R, Aytur S, Carskadon MA (1995) Activity-based assessment of sleep-wake patterns during the 1st year of life. Infant Behav Dev 18:329-337. https://doi.org/10. 1016/0163-6383(95)90021-7

20. Ancoli-Israel S, Cole R, Alessi C, Chambers M, Moorcroft W, Pollak CP (2003) The role of actigraphy in the study of sleep and circadian rhythms. Sleep 26:342-392. https://doi.org/10.1093/ sleep/26.3.342

21. Sadeh A, Lavie P, Scher A, Tirosh E, Epstein R (1991) Actigraphic home-monitoring sleep-disturbed and control infants and young children: a new method for pediatric assessment of sleep-wake patterns. Pediatrics 87:494-499

22. Meltzer LJ, Montgomery-Downs HE, Insana SP, Walsh CM (2012) Use of actigraphy for assessment in pediatric sleep research. Sleep Med Rev 16:463-475. https://doi.org/10.1016/j.smrv.2011.10.002

23. Schoch SF, Kurth S, Werner H (2020) Actigraphy in sleep research with infants and young children: current practices and future benefits of standardized reporting. J Sleep Res 1-15. 30:e13134. https:// doi.org/10.1111/jsr.13134

24. Schoch SF, Jenni OG, Kohler M, Kurth S (2019) Actimetry in infant sleep research: an approach to facilitate comparability. Sleep 42:1-9. https://doi.org/10.1093/sleep/zsz083

25. Zandoná B, Matos S, Bernardi JR, Goldani MZ, Kieling RR, Silva $\mathrm{CH}$ (2020) Influence of intra- and extrauterine factors on infant sleep in the first 6 months of life. J Pediatr (Rio J). 97:160-166. https://doi.org/10.1016/j.jped.2020.01.007

26. Hoeger PH, Harper JI, Baselga E, Bonnet D, Boon LM, Atti MCD, el Hachem M, Oranje AP, Rubin AT, Weibel L, Léauté-Labrèze C (2015) Treatment of infantile haemangiomas: recommendations of 
a European expert group. Eur J Pediatr 174:855-865. https://doi. org/10.1007/s00431-015-2570-0

27. Abarzúa-Araya Á, Navarrete-Dechent CP, Heusser F, Retamal J, Zegpi-Trueba MS (2014) Atenolol versus propranolol for the treatment of infantile hemangiomas: a randomized controlled study. $\mathrm{J}$ Am Acad Dermatol 70:1045-1049. https://doi.org/10.1016/j.jaad. 2014.01.905

28. Sadeh A (2004) A brief screening questionnaire for infant sleep problems: validation and findings for an Internet sample. Pediatrics 113:e570-e577. https://doi.org/10.1542/peds.113.6.e570

29. Buysse DJ, Reynolds CF, Monk TH et al (1989) The Pittsburgh Sleep Quality Index: a new instrument for psychiatric practice and research. Psychiatry Res 28:193-213

30. Squires J, Bricker D, Potter LW (1997) Revision of a parentcompleted developmental screening tool: ages and stages questionnaires. J Pediatr Psychol 22:313-328. https://doi.org/10.1093/ jpepsy/22.3.313

31. Janmohamed SR, De Waard-Van Der Spek FB, Madern GC et al (2011) Scoring the proliferative activity of haemangioma of infancy: the Haemangioma Activity Score (HAS). Clin Exp Dermatol 36:715-723. https://doi.org/10.1111/j.1365-2230.2011.04080.x

32. R Core Team Rf (2013) R: a language and environment for statistical computing

33. Team Rs (2015) RStudio: integrated development for R. RStudio, Inc, Boston, MA

34. Wickham H (2016) ggplot2: elegant graphics for data analysis

35. Zhu H (2018) KableExtra: construct complex table with 'kable'and pipe syntax

36. Bates D, Sarkar D, Bates MD, Matrix L (2007) The lme4 package

37. Wilke CO (2019) cowplot: streamlined plot theme and plot annotations for "ggplot2". R package version 0.9. 4

38. DeWitt P (2018) qwraps2: Quick wraps 2. R package version 0.3. 0

39. Revelle W, Revelle MW (2015) Package 'psych.' Compr R Arch Netw

40. Yamada Y, Shibuya F, Hamada J, Sawada Y, Iga T (1995) Prediction of sleep disorders induced by $\beta$-adrenergic receptor blocking agents based on receptor occupancy. J Pharmacokinet Biopharm 23:131-145. https://doi.org/10.1007/BF02354268

41. Betts TA, Alford C (1985) $\beta$-Blockers and sleep: a controlled trial. Eur J Clin Pharmacol 28:65-68. https://doi.org/10.1007/ BF00543712
42. Betts TA, Alford C (1983) Beta-blocking drugs and sleep. A controlled trial. Drugs 25:268-272

43. McAinsh J, Cruickshank JM (1990) Beta-blockers and central nervous system side effects. Pharmacol Ther 46:163-197. https://doi. org/10.1016/0163-7258(90)90092-G

44. Lam P, Hiscock H, Wake M (2003) Outcomes of infant sleep problems: a longitudinal study of sleep, behavior, and maternal wellbeing. Pediatrics 111:e203-e207. https://doi.org/10.1542/peds.111. 3.e203

45. Martin J, Hiscock H, Hardy P, Davey B, Wake M (2007) Adverse associations of infant and child sleep problems and parent health: an Australian population study. Pediatrics 119:947-955. https://doi. org/10.1542/peds.2006-2569

46. Wintler T, Schoch H, Frank MG, Peixoto L (2020) Sleep, brain development, and autism spectrum disorders: Insights from animal models. J Neurosci Res 98:1137-1149. https://doi.org/10.1002/jnr. 24619

47. Frost S, Saddi V, Teng A, Mallitt KA, Adams S, Williamson B, Wargon O (2020) Propranolol's effects on the sleep of infants with hemangiomas: a prospective pilot study. Pediatr Dermatol 38:1-7. https://doi.org/10.1111/pde.14484

48. Calderón-Castrat X, Velásquez F, Castro R, Ballona R (2019) Oral atenolol for infantile hemangioma: case series of 46 infants. Actas Dermosifiliogr. 111:59-62. https://doi.org/10.1016/j.ad.2019.03. 015

49. Scheer FAJL, Morris CJ, Garcia JI, Smales C, Kelly EE, Marks J, Malhotra A, Shea SA (2012) Repeated melatonin supplementation improves sleep in hypertensive patients treated with beta-blockers: a randomized controlled trial. Sleep 35:1395-1402. https://doi.org/ $10.5665 /$ sleep. 2122

50. Laurens C, Abot A, Delarue A, Knauf C (2019) Central effects of beta-blockers may be due to nitric oxide and hydrogen peroxide release independently of their ability to cross the blood-brain barrier. Front Neurosci 13:1-6. https://doi.org/10.3389/fnins.2019. 00033

51. Luu M, Frieden IJ (2013) Haemangioma: clinical course, complications and management. Br J Dermatol 169:20-30. https://doi.org/ $10.1111 / b j d .12436$

Publisher's note Springer Nature remains neutral with regard to jurisdictional claims in published maps and institutional affiliations.

\section{Affiliations}

\section{Martin Theiler ${ }^{1,2,3}$ (D) - Nicole Knöpfel ${ }^{1,2,3}$ (D) - Susanne von der Heydt ${ }^{4} \cdot$ Agnes Schwieger-Briel $^{1,2,3}$ (D) Isabelle Luchsinger ${ }^{1,2,3}$ (D) Alexandra Smith ${ }^{5} \cdot$ Kristin Kernland-Lang $^{6} \cdot$ Regula Waelchli $^{1,2,3}$ (D) $\cdot$ Kathrin Neuhaus ${ }^{2,3,7}$ (D) $\cdot$ Malcolm Kohler $^{8}$ (D) $\cdot$ Ralph Gnannt $^{2,3,9}$ (D) $\cdot$ Sarah F. Schoch $^{8,10}$ (D) $\cdot$ Lisa Weibel $^{1,2,3}$ (D) Salome Kurth ${ }^{8,10,11}$}

1 Pediatric Skin Center, Dermatology Department, University Children's Hospital Zurich, Steinwiesstrasse 75, CH8032 Zurich, Switzerland

2 Vascular Anomalies Board Zurich, University Children's Hospital Zurich, Zurich, Switzerland

3 Children's Research Center, University Children's Hospital Zurich, Zurich, Switzerland
4 Department of Pediatric Surgery, Charité University Medicine, Virchow Medical Center, Berlin, Germany

5 Division of Pediatric Dermatology, Kantonsspital Winterthur, Winterthur, Switzerland

6 Division of Pediatric Dermatology, Kantonsspital Baden, Baden, Switzerland

7 Pediatric Skin Center, Division of Plastic and Reconstructive Surgery, University Children's Hospital Zurich, Zurich, Switzerland 
8 Department of Pulmonology, University Hospital Zurich, Zurich, Switzerland

9 Division of Pediatric Interventional Radiology, Department of Diagnostic Imaging, University Children's Hospital Zurich, Zurich, Switzerland
10 Center of Competence Sleep \& Health Zurich, University of Zurich, Zurich, Switzerland

11 Department of Psychology, University of Fribourg, 1700 Fribourg, Switzerland 